\title{
LA IDEA DE FEDERALISMO EN LAS CONSTITUCIONES NACIONALES DE ARGENTINA Y COLOMBIA DURANTE LA PRIMERA MITAD DEL SIGLO XIX
}

\author{
THE IDEA OF FEDERALISM IN NATIONAL \\ CONSTITUTIONS OF ARGENTINA AND COLOMBIA \\ DURING THE FIRST HALF OF THE NINETEENTH \\ CENTURY
}

\author{
Alexander Cruz Martínez \\ Universidad de Bogotá Jorge Tadeo Lozano \\ alexandercruzmartinez@utadeo.edu.co
}

\begin{abstract}
SUMARIO: I. INTRODUCCIÓN.- II. EL MODELO FEDERATIVO Y CONFEDERATIVO ARGENTINO.- III. CONSTITUCIONES CENTRALISTAS Y CONSTITUCIONES FEDERALISTAS EN ARGENTINA. - IV. INTENTOS FEDERALES EN COLOMBIA.- V. CONCLUSIONES.
\end{abstract}

Resumen: A partir de las constituciones argentinas y colombianas de la primera mitad del siglo XIX, el presente artículo de reflexión académica presenta de manera comparada el enfrentamiento entre centralistas y federalistas, y el triunfo del federalismo, como forma de organización estatal que sirvió de base para legitimar los procesos de consolidación política y administrativa de ambas naciones en aquel momento histórico.

Abstract: From the argentine and colombian constitutions of the first half of the nineteenth century, this article presents a comparative study about the clash between centralists and federalists, and the triumph of federalism as a form of state organization that provided the basis for legitimizing processes of political and administrative consolidation of both nations at that historical moment.

Palabras clave: Federalismo, centralismo, Argentina, Colombia, siglo XIX.

Key Words: Federalism, centralism, Argentina, Colombia, 19th century.

\section{INTRODUCCIÓN}

Las relaciones existentes entre el poder político y la administración de los territorios que lo integran se concretan en las formas de Estado, entiendas como cualquiera de las manifestaciones puras o intermedias entre los modelos unitario y federal ${ }^{1}$; lo que a su vez constituye uno de los elementos que siempre está

1 De acuerdo con Burdeau, el estado unitario es "el que solo posee un centro de impulsión politica y gubernamental, el poder público, en la totalidad de sus atributos y funciones cuenta en él con único titular, que es la persona jurídica del estado. Todos los individuos colocados bajo su soberanía obedecen a una misma y única autoridad, viven bajo el mismo régimen constitucional y están regidos por las mismas leyes". Según el mismo autor el estado federal es el que "... apareciendo como único en las relaciones internacionales, está constituido por Estados miembros que 
presente en la parte orgánica de las constituciones modernas. Esto con el fin de dar cimiento y legitimar las macroestructuras que coadyuvan al cumplimiento de los postulados estatales y que sirven a sus ciudadanos. Sin este elemento, el Estado pierde su esencia y se convierte en un cuerpo amorfo y maleable.

Desde 1853, Argentina es un Estado federal mientras que Colombia adoptó un modelo unitario desde 1886, que hoy está matizado por la descentralización y la autonomía de sus entes territoriales. No obstante, entre 1853 y 1886 Colombia fue federal. Para llegar al federalismo, en ambas naciones hubieron de acontecer una serie de sucesos que guardan como similitud el enfrentamiento acérrimo entre partidarios centralistas y federalistas.

El presente artículo de reflexión tiene como objetivo explicar, de forma comparada, la evolución histórica de la idea de federalismo en el constitucionalismo argentino y colombiano durante la primera mitad del siglo XIX. Para dar cumplimiento a este propósito, este escrito se halla dividido en cuatro secciones. La primera explica la diferencia entre los modelos federativos y confederativos en Argentina; la segunda hace un recuento de las principales características de los pactos y constituciones federales y centralistas en Argentina; la tercera describe los intentos federativos en Colombia; y la última presenta algunos elementos destacados del ejercicio histórico comparativo a manera de conclusión.

\section{EL MODELO FEDERATIVO Y CONFEDERATIVO ARGENTINO}

En el modelo federal cada Nación es libre de denominarle a sus territorios autónomos como mejor se acomode a su tradición histórica. Estados Unidos le llamó estados al igual que lo hizo Colombia en el periodo 1853-1886, mientras que Argentina optó por la denominación de provincias. Según Rosatti², los romanos utilizaron el término provinco para designar los territorios conquistados. Hoy en día, a la luz del derecho argentino se entiende que como punto de partida no existe una relación de dominio frente al Estado nacional, sino de convivencia a partir de la Constitución Nacional. Esto se concreta en un status de "autonomía constitucionalmente establecida y constitucionalmente regulada".

Según este autor ${ }^{3}$, la autonomía se entiende como a) autonormatividad constituyente que significa facultad para establecer en su norma fundante sus

conservan ciertas prerrogativas de soberania interna y sobre todo el poder legislativo. Lo que distingue estos Estados miembros de las colectividades descentralizadas de un Estado unitario es que los primeros participan en la formación de la voluntad del Estado central... Además los Estados miembros disponen de una competencia propia, fijada por una Constitución federal en materia legislativa, ejecutiva o jurisdiccional. La distribución de las competencias entre gobierno federal y gobiernos locales se hace ya por la enumeración de las respectivas competencias, ya por la enumeración de las competencias federales, lo que presume que el resto es de la competencia de los Estados miembros, ya por la enumeración de la competencia de los Estados miembros, presumiéndose lo contrario". Ver Georges Burdeau, Derecho Constitucional e Instituciones Politicas, traducción de la $18^{a}$ ed. francesa realizada por Ramón Falcón Tello, Editora Nacional Cultura y Sociedad Torregalindo, Madrid, 1981, pp. 40, 74.

2 Horacio Rosatti, Tratado de derecho constitucional, Tomo II, Rubinzal Culzoni Editores, Buenos Aires, 2010, p. 572.

3 Ibíd. 
La idea de federalismo en las constituciones de Argentina y Colombia durante la ...

objetivos y estructura de base ${ }^{4}$, b) autocefalia o capacidad para elegir sus propias autoridades $^{5}$, c) autarquía $\mathrm{o}$ capacidad para gestionar $\mathrm{o}$ satisfacer sus necesidades económicas y financieras a partir de la tenencia de recursos propios y su libre disposición, y d) autodeterminación política que consiste en el reconocimiento de garantías frente a que las provincias se rijan por sus instituciones sin injerencia del Gobierno federal.

También existe un principio de igualdad jurídica que implica, que sin importar si se trata de una provincia originaria o no originaria, tiene el mismo status, aunque en la carta se consagren excepciones como la del derecho de Buenos Aires para normar sobre el Banco de la Provincia, sustrayéndolo del poder ejercido por el Banco Central; la sobrerepresentación en la Cámara de Diputados de algunas provincias y la asignación de subsidios especiales del Tesoro Nacional al no poder cubrirse los gastos ordinarios de algunas de ellas, entre otros.

Adicionalmente se les permite celebrar tratados parciales para efectos de administración de justicia, de asuntos económicos y de trabajos de utilidad, tal como lo dispone en el artículo 125 de la Constitución Nacional argentina, con conocimiento del Congreso federal. Para la formación de las provincias, el artículo 13 de esa Carta establece las hipótesis de anexión, división o fusión ${ }^{6}$.

En Argentina, desde el ámbito histórico, existen dos tipos de provincias, unas que dieron origen al estado nacional y otras que fueron creadas por el Estado nacional. Rosatti ${ }^{7}$ llama a las primeras provincias originarias y a las segundas provincias sobrevinientes, en razón a que fueron creadas por una Ley del Estado. Son originarias porque protagonizaron el proceso constituyente de 1853-1860: Buenos Aires, Córdoba, Catamarca, Corrientes, Entre Ríos, Jujuy, Mendoza, la Rioja, Salta, Santiago del Estero, San Juan, Santa Fe, San Luis y Tucumán. Son sobrevinientes Chaco, Chubut, Formosa, La Pampa, Misiones, Neuquén, Río Negro, Santa Cruz, Tierra del Fuego, Antártida e Islas del Atlántico Sur.

Fue el artículo 1 de la Constitución Nacional ${ }^{8}$ el que adoptó el modelo federal. Adicionalmente, el artículo 35 de la misma norma señaló que "Las denominaciones adoptadas sucesivamente desde 1810 hasta el presente, a saber: Provincias Unidas del Rio de la Plata; República Argentina, Confederación Argentina, serán en adelante nombres oficiales indistintamente para la designación

4 Ver artículos 123 y 5 de la Constitución Nacional de Argentina.

5 Ver artículo 122 de la Constitución Nacional de Argentina.

6 El artículo 13 de la Constitución Nacional de Argentina señala que "Podrán admitirse nuevas provincias en la Nación; pero no podrá erigirse una provincia en el territorio de otra u otras, ni de varias formarse una sola, sin el consentimiento de la Legislatura de las provincias interesadas y del Congreso".

${ }^{7}$ Horacio Rosatti, Tratado de derecho constitucional, op. cit., p. 572.

8 Chiaramonte, con el fin de ambientar la evolución del federalismo, explica que el vocablo argentino, a finales del período colonial y principios del periodo de independencia, sólo se refería al ámbito de Buenos Aires. De forma similar, ocurre con el término rioplatense o Río de la Plata que también se identifica con el territorio de Buenos Aires como capital de Virreinato del Río de la Plata. Ver: José Carlos Chiaramonte, "El federalismo argentino en la primera mitad del siglo XIX" en Marcelo Carmagnani (coord.). Federalismos latinoamericanos: México/Brasil/Argentina, Fondo de Cultura económica, México, 1993, p. 86. 
del Gobierno y territorio de las provincias...", lo cual significa que para la época de expedición del texto, los términos federación y confederación eran equivalentes.

Actualmente estos son conceptos que tienen una definición precisa y diferente para cada uno de ellos y no pueden confundirse. Levaggi ${ }^{9}$ sostiene que la federación es una forma de estado que implica la soberanía compartida entre la nación y las provincias, que son para el caso argentino los equivalentes a los estados federados que la integran. Por su parte, la confederación es una asociación de estados independientes unidos a través de un tratado que busca unos fines específicos en el ámbito internacional.

Esta claridad doctrinal no existía para la época puesto que se entendía que existía entre ellos una relación de género a especie. La equiparación de ambos términos no fue simplemente semántica sino que tuvo unas consecuencias sustanciales en el contexto histórico. Rosatti ${ }^{10}$ explica que la asimilación no fue antojadiza pues encarna la situación preconstitucional de los pueblos emancipados de la dominación extranjera antes de la Constitución de 1853/60. Esto es relevante no solo desde el ámbito histórico sino además desde el jurídico constitucional porque esa Constitución constituiría entonces un acto fundacional.

La invención del Estado federal indudablemente fue producto de los padres fundadores de los Estados Unidos. La literatura anterior a la constitución de Filadelfia denominaba federalismo a formas de unión entre estados tales como la Liga Aquea en la Antigua Grecia o la Confederación Helvética. Es innegable la influencia del modelo estadounidense en la Constitución argentina, como también la existencia de matices muy concretos totalmente originales aportados por obras criollas como la de Juan Bautista Alberdi titulada "Bases y Puntos de Partida Para la Organización Política de la República Argentina".

Como se verá más adelante, la Carta de 1831 no adoptó el modelo federal sino que organizó una confederación puesto que los representantes de cada provincia eran agentes diplomáticos de estados que se autoproclamaban como independientes. Chiaramonte ${ }^{11}$ señala que el federalismo argentino puede dividirse en dos etapas. La primera corresponde al periodo anterior a 1831 caracterizado por la discusión en torno al modelo que más convenía, es decir la implantación del centralismo o el federalismo. La segunda es la posterior a ese año, en el cual la discusión se centra respecto a cuáles eran las características que debía tener ese federalismo y qué implicaba diferenciarlo de la forma confederativa. Al no tener claras tales vicisitudes, se debilitó la comprensión y asimilación del modelo.

Lo anterior es concomitante con las discusiones en torno a si la Constitución de 1853/60 fue un acto declarativo de la existencia de la Nación Argentina conformada con anterioridad o si esa Constitución fue el acto fundacional de la misma. En ese escenario, Rosatti es partidario de lo segundo. Él sostiene que una vez se da el proceso de independencia frente a España, los Estados-provincias se

9 Abelardo Levaggi, Confederación y federación en la génesis del estado argentino, Universidad de Buenos Aires, Buenos Aires, 2007, p.11.

10 Horacio Rosatti, Tratado de derecho constitucional, op. cit., p. 453.

11 José Carlos Chiaramonte, "El federalismo argentino en la primera mitad del siglo XIX", op. cit., p. 82 . 
La idea de federalismo en las constituciones de Argentina y Colombia durante la ...

agremiaron manteniendo internamente su soberanía y su derecho a separarse. Esta situación cambió sustancialmente en la Constitución de 1853/60, que niega esa posibilidad.

La tesis mayoritaria concibe que en 1853 se produjo un acto contractual que fundó el Estado argentino. De otra parte existe la tesis de que las naciones preexistian antes de la formación la República argentina. Hay otro elemento importante que es el del caudillismo, clave en la formación del federalismo argentino. Rosatti ${ }^{12}$ explica que el federalismo es la consecuencia de la lucha por el poder económico librada por el interior mediterráneo, que necesitaba desarrollar su incipiente industria artesanal, y el interior litoraleño dedicado a la ganadería que rechazaba la burguesía porteña permeada por el librecambismo europeo.

Existieron también factores geográficos que produjeron el aislamiento de muchas comunidades, lo que sumado al poder de los caudillos locales propició la fórmula federal, extraída del modelo norteamericano. Ramos Mejía ${ }^{13}$ desarrolló una explicación, la cual ha sido llamada tesis genética, en la que asevera que el federalismo es la evolución natural de comunalismo colonial. De otra parte, Alberdi y Bidart Campos ${ }^{14}$ suponen una interpretación pluralista del fenómeno que se funda en varios factores; no obstante, para el primero el federalismo es una cuestión más de tipo administrativo, mientras que para el segundo es un asunto de trascendencia politica fundamental.

En otras palabras, surge la pregunta respecto a si el proceso histórico confluye en una evolución sociológica que afianzó la necesidad del federalismo, o si por el contrario este fue el producto de la imposición de los caudillos en defensa de las autonomías provinciales y de sus intereses locales, para encarar el deseo centralista porteño en el que los caudillos jugaron un papel preponderante. Entiendo que ambos elementos estuvieron presentes.

\section{CONSTITUCIONES CENTRALISTAS Y CONSTITUCIONES FEDERALISTAS EN ARGENTINA}

Existen tres momentos históricos que desde el ámbito constitucional argentino, son muy importantes. El primero se da en 1810 con la proclama de independencia de algunos territorios, el segundo se ocasiona con la expedición de la Constitución de 1831 y el tercero aparece con la aprobación de la constitución de 1853. El lapso comprendido entre los años 1810-1853 se caracterizó naturalmente por una inestabilidad y una lucha de fuerzas en pro de implantar un modelo de administración jurídico político uniforme para todo el territorio. Fueron muchas las disputas y fracasos de las reuniones y de las asambleas que fueron convocadas, hasta que finalmente triunfa el federalismo que se ha mantenido hasta nuestros dias.

Antes de 1810 y bajo el yugo español, una de las características más importantes de la forma administrativa colonial fue la centralización politica y

\footnotetext{
12 Horacio Rosatti, Tratado de derecho constitucional, op. cit., p. 557.

13 Citado por Horacio Rosatti, Tratado de derecho constitucional, op. cit., p. 559.

14 Citado por Horacio Rosatti, Tratado de derecho constitucional, op. cit., p. 560.
} 
administrativa en cabeza del Rey. Para ello se asistía del Consejo de Indias en el que había representación de los virreyes. En 1776 se crea el Virreinato del Río de la Plata, para administrar muchos de los territorios ubicados en lo que hoy es Argentina, tarea que no era fácil dado lo basto del territorio y las condiciones geográficas y sociales que fueron creando una serie de fuerzas que más tarde resultaron aliadas y enfrentadas, según su conveniencia.

Con la Revolución del 25 de mayo de 1810 se nombró la primera junta provincial gubernativa ${ }^{15}$ de Buenos Aires, que en términos políticos, significó el cambio hacia una soberania en cabeza del pueblo. Gargaro ${ }^{16}$ sostiene que hay un vestigio de federalismo cuando la Junta de Comisión de la expedición militar al Alto Perú señaló que si los pueblos del interior quisieran formar juntas que subrogasen el mando de sus gobernadores, no se debía hacer oposición alguna, siempre que mantuviesen su dependencia con la de Buenos Aires.

En 1811 se empezó a discutir el modelo de Estado y la conveniencia de implantar el norteamericano con miras a mantener la unidad territorial, teniendo en cuenta que debía primar la libertad y la igualdad. El Congreso de Tucumán declaró la independencia el 9 de julio y trasladó sus reuniones a la capital. Mendoza y Córdoba fueron los primeros territorios que reclamaron el derecho a formar juntas provinciales y a las autonomias intendiles. El Cabildo de Jujuy, en comunicación del 19 de febrero de 1811, desconociendo la creación de las juntas provinciales formuló a la Junta Grande un petitorio de naturaleza políticoeconómico haciendo una crítica al sistema de gobierno reinante y especialmente a la creación de intendentes ${ }^{17}$.

El naciente autonomismo se vio reflejado en algunas disposiciones del reglamento de febrero 1811 de las juntas provinciales que constituye la primera manifestación de soberanía y punto de partida en la conformación de las provincias originarias. El 12 de octubre de 1811 se suscribió el tratado de Paraguay, en el que se reconoció la independencia de esa nación, al mismo tiempo que se planteó que seguiría unido al resto de provincias en una alianza indisoluble. Se trataba de una apuesta contradictoria en un modelo federal pero no para uno confederal. Pese a lo anterior, el 19 de abril de 1813, entre Rondeau y Artigas se suscribió la Convención de la Provincia Oriental del Uruguay, en la cual se estipuló que Uruguay tenía el mismo estatus de las demás provincias como parte integrante de las Provincias Unidas del Río de la Plata.

En 1815 el Congreso expidió el Estatuto Provisional y el 23 de junio de 1815 se celebró en Concepción del Uruguay, entre Córdoba, Santa Fe, Entre Ríos, Corriente, Misiones y la Banda Oriental, el Pacto de la Liga Federal. En 1816 el Congreso General Constituyente declaró la independencia en Buenos Aires y se

15 El gobierno municipal, que era una institución hispánica denominada cabildo o ayuntamiento siguió funcionando con la ayuda de una junta de gobierno elegida en cada villa por los mismos vecinos. Fue reformada en los estatutos provisorios de 1815 y 1817 fijando un método democrático de elección para todos sus miembros; sin embargo, cuando se consolidaron las legislaturas provinciales, estas entraron en conflicto con los cabildos porque se superponian en algunas de sus funciones. En consecuencia los cabildos fueron suprimidos en la década de 1820.

16 Alfredo Gargaro, Origenes del federalismo argentino.

Tomado de http://www.fundacioncultural.org/revista/nota1_33.html [Consultado: 20 de noviembre de 2013].

17 Alfredo Gargaro, Orígenes del federalismo argentino, op. cit. 
La idea de federalismo en las constituciones de Argentina y Colombia durante la ...

encargó de redactar la "Constitución de las Provincias Unidas en Sudamérica". El 28 de mayo de 1816, Buenos Aires y Santa Fe celebraron un tratado en el cual la primera reconoció a la segunda la libertad e independencia hasta tanto no se dictara una Constitución por parte del Congreso soberano. Posteriormente se expidió el Reglamento Provisional de 1817. Lo anterior quedó en vilo a partir del 22 de abril de 1819, cuando se proclamó una Constitución con régimen unitario $^{18}$ la cual fue jurada el 25 de mayo de $1819^{19}$.

El texto constitucional dividió los derechos entre los del Estado y los de los particulares. Señaló en su sección V, que la Nación tenía derecho a reformar su Constitución, el derecho a la separación de poderes, el derecho a la representación de las corporaciones y responsabilidad de los representantes, el derecho a que ninguna autoridad fuera superior a la ley y deber de obediencia, el derecho a delegar el ejercicio de su soberanía y a reservar la facultad de nombrar sus representantes, y la de ejercer libremente el poder censorio por medio de la prensa. En esta constitución quedó establecido que es el Congreso quien demarca el territorio del Estado y fija los límites de las provincias ${ }^{20}$ pero no dijo que pudiera crearlas pues no les dotó de tal facultad, tampoco estableció las competencias de las provincias.

El año 1820 fue el de la anarquía política pues prácticamente desapareció toda autoridad nacional. A raíz de la caída de Rondeau en la batalla de Cepeda, el Congreso fue disuelto y se dio caducidad a la Constitución de 1819. Se presentó otro giro sustancial a partir del reconocimiento expreso del federalismo gubernativo de las provincias contratantes y la convocatoria a nuevo Congreso General en el Convento de San Lorenzo mediante el tratado del Pilar del 23 de febrero entre Buenos Aires, Santa Fe y Entre Ríos, en el que las partes admitieron la federación pero sometida a la autoridad del Congreso, aspirando a la organización de un gobierno central. Por su parte, el 24 de abril del mismo año, se formó la Liga (pacto) de Avalos entre Misiones, Corrientes y la Banda Oriental en el cual se reiteró el principio federativo. Por su parte, el 25 de noviembre de 1820 se suscribió el Pacto de Benegas entre Santa Fe y Buenos Aires para disponer la inmediata reunión del Congreso Nacional en Córdoba ${ }^{21}$.

A continuación, el 4 de mayo de 1821, se suscribió el Pacto de Cuyo, entre Mendoza, San Luis y San Juan para establecer una constitución común de tipo regional prescribiendo que acudirian en cualquier tiempo a la reunión del Congreso Nacional cuando fuese convocado. Posteriormente, el 19 de septiembre de 1821 entre Tucumán y Santiago del Estero, se suscribió el Pacto de Tucumán, en el que se declararon unidas y a la espera de la reunión del Congreso Nacional.

El 25 de enero de 1822 se suscribió el Tratado del Cuadrilátero entre Buenos Aires, Santa $\mathrm{Fe}$, Entre Ríos y Corrientes para formar una paz y unión permanente, quedando a la espera de la reunión del Congreso. Seguido, el 22 de agosto de ese mismo año, San Juan, San Luis y Mendoza, se unieron en el

18 Germán Bidart Campos, Historia Politica y Constitucional Argentina, Tomo I, Ediar, Buenos Aires, 1976, p. 151 .

19 Es la primera constitución. Tiene como antecedentes los proyectos constitucionales de la Asamblea del año XIII, la Constitución de los Estados Unidos de 1787, entre otras.

20 Artículo 40 de la Constitución Nacional de Argentina.

21 Germán Bidart Campos, Historia Politica y Constitucional Argentina, op. cit., p. 151. 
tratado de San Miguel de las Lagunas pensando en conformar una autoridad central que por fin convocara a la tan esperada reunión del Congreso Nacional.

En consecuencia, el Congreso General sesionó entre 1824 y 1827 para legislar y asumir las tareas constituyentes. En 1826 se sancionó una constitución que estableció en su artículo 7 un Estado unitario en los siguientes términos: "... La nación argentina adopta para su gobierno la forma representativa, republicana, consolidada en unidad de régimen...". Sin embargo más adelante, en otras normas desdibujó el modelo, creando una mixtura entre los regimenes unitario y federal pues otorgó la posibilidad de elección de diputados por las respectivas provincias.

Esta Constitución fijó un régimen de administración provincial ${ }^{22}$, no mencionó derechos del Estado aunque sí señaló que las provincias serian administradas por un consejo al cual le otorgó el derecho de petición “... directamente a la legislatura nacional, y al presidente de la república, o para reclamar cuanto juzguen conveniente a su propia prosperidad, o para exigir la reforma de los abusos, que se introduzcan, en su régimen, y administración”.

Como consecuencia de la adopción del régimen unitario y de que fuera de iniciativa de Buenos Aires, además de otras circunstancias, fue rechazado por la mayoria de las provincias y el Presidente Rivadavia cesó en el poder después de la firma del tratado de paz firmado con Brasil el 24 de mayo de 1827. A través del Pacto Multilateral de Córdoba, suscrito el 17 de mayo de 1827 por Santa Fe, Entre Ríos, Córdoba, Corrientes, Santiago del Estero, Salta, La Rioja, Mendoza, San Juan, San Luis y La Banda Oriental se hizo expresa la oposición. Todas estas provincias reiteraron su compromiso con el modelo federal y el rechazo al unitarismo como forma de estado 23.

A partir del pacto anterior, Mendoza, San Luis y San Juan, suscribieron el 1 de abril y el 2 y 3 de junio de 1827 el Tratado de Huanacache en el cual reafirmaron las relaciones pacificas y quedaron a la espera de que fuera adoptada una Constitución para toda la república. En ese mismo año, el 21 de septiembre, Buenos Aires y Córdoba firmaron un nuevo tratado para apoyarse mutuamente con la intención de formar nación y de cooperar con la guerra contra Brasil. En este se señaló la celebración de una asamblea para el mes de noviembre con la presencia de dos diputados por provincia que sirviera de colegio electoral para designar un ejecutivo de orden nacional provisorio y la convocatoria al Congreso, reiterándose la forma federativa.

Con el tratado del 24 de septiembre de 1827, Corrientes y Entre Ríos formaron una alianza perpetua sin perjuicio de que el Pacto Nacional se celebrara más adelante. Días más tarde, el 2 de octubre de 1827, entre Buenos Aires y Santa Fe, se llegó a un acuerdo para influenciar en que se convocara a una convención nacional, así mismo el 29 de octubre de 1827, entre Buenos Aires y Entre Ríos, se declaró que se debía apresurarse la reunión con las demás provincias. El 11 de diciembre de 1827 entre Buenos Aires y Corrientes se firmó un pacto que las obligó a ayudarse mutuamente y se reiteró en la necesidad de hacerse la convención para nombrar un gobierno nacional y expedir una constitución con vocación federal.

\footnotetext{
22 Artículos 130 a 158 de la Constitución Nacional de Argentina.

23 Germán Bidart Campos, Historia Politica y Constitucional Argentina, op. cit., p. 152.
} 
La idea de federalismo en las constituciones de Argentina y Colombia durante la ...

En 1829, entre Córdoba y San Luis, se firmó un nuevo pacto a fin de sostener el modelo federal porque era unánime la intención de las provincias y porque ya se habian pronunciado a su favor en diferentes escenarios cuando habian estado en plena libertad. Los pactos del 18 de octubre de 1929 entre Santa Fe y Buenos Aires y del 27 de octubre de 1829 entre Buenos Aires y Córdoba convocaron igualmente a la reunión del Congreso Nacional.

Luego de un periodo de anarquía y bajo la tendencia federal, el 6 de diciembre de 1829, el general Juan Manuel de Rosas asumió la gobernación de Buenos Aires y formó una liga unitaria. El 23 de febrero de 1830 Santa Fe y Corrientes se comprometieron a emplear sus buenos oficios para promocionar que otras provincias entraran en el pacto siempre que aprobaran el sistema federal. El 23 de marzo de 1830 entre Buenos Aires y Corrientes, se reforzó la consolidación de la liga de las cuatro provincias del litoral que adoptaron de forma definitiva el sistema federal. El 3 de mayo de 1830 entre Corrientes y Entre Ríos se previó que existiera una convención preliminar que reiterara la forma federal ${ }^{24}$.

Como manifestación de disidencia, el 5 de julio de 1830 se formó una liga entre Córdoba, Catamarca, San Luis, Mendoza y La Rioja. En esta acordaron como causa común la expedición de la Constitución del Estado, pero declarando no ligarse a sistema político alguno, ni aceptar la Constitución que otorgara el Congreso Nacional. Como reacción, Buenos Aires, Santa Fe y Entre Ríos se unieron el 4 de enero de $1831^{25}$ en un tratado de tendencia federal en el que se

\footnotetext{
24 Ibid.
}

25 Algunos apartes del documento manifiestan que "Deseando los Gobiernos de Buenos Aires, Entre Rios y Santa Fe estrechar cada vez más los vinculos que felizmente los unen, y creyendo que asi lo reclaman sus intereses particulares... y, finalmente, considerando que la mayor parte de los pueblos de la República ha proclamado del modo más libre y espontáneo la forma de gobierno federal, han convenido en los articulos siguientes: Art. 1. Los Gobiernos de Buenos Aires, Entre Rios y Santa Fe, ratifican y declaran en su vigor y fuerza todos los tratados anteriores celebrados entre los mismos Gobiernos, en la parte que estipulan paz firme, amistad y unión estrecha y permanente: reconociendo reciprocamente su libertad, independencia, representación y derechos. Art. 2. Las provincias de Buenos Aires, Entre Rios y Santa Fe se obligan a resistir cualquiera invasión extranjera que se haga; bien sea en el territorio de cada una de las provincias contratantes, o de cualquiera de las otras que componen el Estado Argentino. ...Art. 15. Ínterin dure el presente estado de cosas, y mientras no se establezca la paz pública de todas las provincias de la República, residirá en la capital de Santa Fe, una comisión compuesta de un diputado por cada una de las tres provincias litorales, cuya denominación será Comisión Representativa de los Gobiernos de las Provincias Litorales de la República Argentina, cuyos diputados podrán ser removidos al arbitrio de sus respectivos Gobiernos, cuando lo juzguen conveniente, nombrando otros inmediatamente en su lugar. Art. 16. Las atribuciones de esta Comisión serán: $1^{a}$. Celebrar tratados de paz a nombre de las expresadas tres provincias, conforme a las instituciones que cada uno de los diputados tenga de su respectivo Gobierno, y con la calidad de someter dichos tratados a la ratificación de cada una de las tres provincias. $2^{a}$. Hacer declaración de guerra contra cualquier otro poder, a nombre de las tres provincias litorales, toda vez que éstas estén acordes en que se haga tal declaración. $3^{a}$. Ordenar se levante el ejército, en caso de guerra ofensiva o defensiva, y nombre el general que deba mandarlo. $4^{a}$. Determinar el contingente de tropa con que cada una de las provincias aliadas deba contribuir, conforme al tenor del artículo trece. $5^{a}$. Invitar a todas las demás provincias de la República, cuando estén en plena libertad y tranquilidad, a reunirse en federación con las tres litorales, y a que por medio de un Congreso General Federativo se arregle la administración general del país bajo el sistema federal, su comercio interior y exterior, su navegación, el cobro y distribución de las rentas generales, y el pago de la deuda de la República, consultando del mejor modo posible la seguridad y engrandecimiento general de la República, su crédito interior y exterior, y la soberanía, libertad e independencia de cada una de las provincias". 
estableció que en Santa Fe residiría una comisión de gobierno; además insistieron en la necesidad de un gobierno federal.

Posteriormente se adhirieron las provincias de Mendoza, Corrientes, Córdoba, Santiago del Estero, La Rioja, Tucumán, San Luis y Catamarca e informalmente, Salta y San Juan. El pacto hizo que se enfrentaran Buenos Aires y Corrientes, puesto que esta última intentó incorporar ciertas políticas económicas de corte proteccionista, contrarias al librecambio defendido desde la capital, que afectarian la propiedad de las rentas porteñas y la libre navegación de los libros Paraná y Uruguay ${ }^{26}$.

Esto llevó a que en el periodo 1831-1852, las catorce provincias tuvieran una forma de organización gestacional del modelo federal que se implantó con todo vigor en 1853. Si bien, Rosas prorrogó durante su largo mandato la expedición de una Constitución, su mayor logro fue el de consolidar la unidad de la confederación, incluso las provincias delegaron en el gobernador de Buenos Aires el manejo de las relaciones exteriores.

En 1851 se dio otro cambio sustancial en la historia argentina. Con el propósito de reorganizar el país, se produjo el levantamiento del caudillo federal de Entre Ríos, Nicolás Justo José de Urquiza, contra el gobernador Juan Manuel Rosas, lo cual conllevó a que este último fuera derrotado en la batalla de Caseros del 3 de febrero de 1852. Más tarde, el 6 de abril del mismo año se suscribió el protocolo de Palermo entre Buenos Aires, Entre Ríos, Corrientes y Santa Fe, que resolvió que cada uno de los gobiernos del pacto federal de 1831 nombrara su representante en Santa Fe para la convención.

Para reforzar lo anterior, el 31 de mayo de 1852 se suscribió el acuerdo de San Nicolás de los Arroyos entre los gobernadores y capitanes generales de Buenos Aires, Entre Ríos, Catamarca, Corrientes, San Luis, San Juan, Tucuman, Mendoza, Santiago del Estero, La Rioja y Santa Fe, con adhesión posterior de Córdoba, Salta y Jujuy el 1 de julio de 1852. En este se estableció la convocatoria a una Convención Constituyente ${ }^{27}$.

También se reconoció que el Pacto Federal de 1831 era una Ley Fundamental a la cual se adhirieron todas provincias. El artículo 2 soporta la expedición del pacto al señalar que estando las provincias en plena libertad y tranquilidad y conforme con lo dispuesto en el artículo 16 del Pacto de 1831 era viable la reunión de un Congreso General Federativo que organizara la administración general de la Nación bajo el sistema federal. Además se recordó que todas las provincias eran iguales en derechos, como miembros de la Nación, razón por la cual el soberano Congreso General Constituyente de la Confederación Argentina se integraría con dos diputados por cada provincia.

Para Buenos Aires, ello significaba entregar el puerto y sus cuantiosos ingresos, razón por la cual dimitió del Acuerdo. Con esta excepción se reunieron los representantes de las trece provincias en el Cabildo de Santa Fe y se dedicaron a la redacción del texto constitucional, sancionado el 1 de mayo de 1853 y jurado el 9 de julio del mismo año por todas las provincias.

26 José Carlos Chiaramonte, "El federalismo argentino en la primera mitad del siglo XIX”, op. cit., p. 87 .

27 Arturo Enrique Sampay, Las constituciones de la Argentina 1810-1972,Eudeba, Buenos Aires, 1974 , p. 330. 
La idea de federalismo en las constituciones de Argentina y Colombia durante la ...

Santiago Derqui asumió la presidencia apoyado por Urquiza y con muy escaso poder. En la batalla de Cepeda, se resolvió la incorporación de Buenos Aires a la confederación, pero este proceso se dio años más tarde. Así las cosas, el orden constitucional se completó en 1860 con la entrada de Buenos Aires. Después vendrian las reformas de 1866, 1898, 1957 y 1994, y consigo la arquitectura normativa original se fue moldeando hasta llegar a la vigente siendo "una de las prescripciones con mayor duración en su vigencia en el mundo"28.

Juan Carlos Gioja ${ }^{29}$ asume que:

Por otra parte, y a pesar del doloroso proceso a través del cual se unieron las distintas provincias, nuestros constituyentes manifestaron una real convicción federalista al otorgarles su personalidad jurídica y política. Cabe recordar al doctor Juan A. González Calderón, quien rescata el pensamiento de que las provincias argentinas en ningún momento de nuestra historia se consideraron independientes ni desligadas de todo vínculo nacional; el pueblo era el pueblo de las provincias en su conjunto. La Constitución de 1853 denomina a esta unión "Confederación Argentina", expresión duramente fustigada por Sarmiento ya que, según él, significaba aceptar que se había conformado una asociación o liga entre diversos Estados.

E1 título original de la Carta Magna de 1853, "Constitución de la Confederación Argentina" fue modificado después de 1860, cambiando el término "Confederación" por "Nación" sin que hubiera acto constituyente expreso al respecto. La Convención de 1949 ratificó esa modificación en el texto ordenado "fidedigno" que aprobó, considerando que la representación era de todo el pueblo de la Nación en una unidad de fines e ideales.

Esta representación del pueblo se confirma en el artículo 44 de la Constitución al establecer que el Congreso estará compuesto por dos Cámaras, una de diputados que representan al pueblo de la Nación y otra de senadores que representan a las provincias y a la ciudad de Buenos Aires, garantizando así el sistema federal.

Levaggi señala que las constituciones de corte federalista no fueron en su totalidad copia de la Carta de Filadelfia, por el contrario incorporaron elementos novedosos y propios de la realidad de la época. El único proyecto real de constitución federal fue el de 1813 copiado de fuentes norteamericanas. Incluso hubo un dilema respecto a si se adoptaba una república o una monarquía, como forma de gobierno, asunto que solo fue resuelto en los proyectos de 1815 y 1819 asociados a la idea de monarquía ${ }^{30}$, pero no en los demás.

28 Raúl Gustavo Ferreyra, "1852: Sobre las bases de Juan Bautista Alberdi y la constitución federal en el tiempo", Revista Contextos 3, Defensoría del Pueblo de la Ciudad Autónoma de Buenos Aires, Buenos Aires, 2012, p. 70.

29 Juan Carlos Gioja, Constitución de la Nación Argentina, Corte Suprema de Justicia de la Nación / Biblioteca del Congreso de la Nación / Biblioteca Nacional, Buenos Aires, 2010, p. 19.

\footnotetext{
30 Abelardo Levaggi, Constitucionalismo argentino 1810-1850, Revista Electrónica Iushistoria, $\mathrm{N}^{\circ}$ 2, Buenos Aires, Universidad del Salvador, Octubre 2005. Disponible en http://static.scribd.com/docs/d9wd8aaxxzohf.swf?INITIAL_VIEW=width [Consultado: 2 de diciembre de 2013].
} 
La pretensión monárquica se basó en el sistema inglés y en la Constitución de Cádiz, pero no como absoluta tal como se dio en la Francia prerrevolucionaria. Incluso se pensó que se debía coronar a un descendiente de los incas. Los más fervientes opositores fueron los federalistas que se encargaron de dejar en claro en el proyecto de 1813 que cada provincia tuviera una forma republicana de gobierno. La discusión en torno a la implantación del sistema centralista se posicionó en los sectores ilustrados afrancesados que se inclinaron por el modelo centralizado, sin embargo los grupos tradicionalista de estirpe rural se inclinaron por el modelo federal.

\section{INTENTOS FEDERALES EN COLOMBIA}

En el año de 1810 se firmó el acta de independencia de Colombia frente a España que en estricto sentido no fue "de independencia" sino de adhesión a Fernando VII y de protesta contra la invasión napoleónica a España. A decir de Pérez Escobar ${ }^{31}$ el modelo elegido por la Junta Suprema de Gobierno fue el de unión personal, el cual consiste en la asociación de dos o más Estados, que si bien son gobernados por un mismo jefe, cada uno sigue conservando su soberanía interna y externa. Adicionalmente, se proclamó la forma de un estado federal inspirado en el modelo norteamericano a partir de las provincias existentes en el territorio de la Nueva Granada.

Esto posibilitó que inmediatamente algunas de sus provincias expidieran sus constituciones políticas: Cundinamarca y Tunja en 1811, y Antioquia y Cartagena de Indias en 1812. Las demás no lo hicieron, razón por la cual se creó un sistema de organización sui generis en el que unas estaban atadas al poder central y otras se proclamaron como independientes. Desde Santafé de Bogotá se hizo un llamado a las provincias para conformar un sistema inspirado en el modelo norteamericano, sin embargo ellas dejaron ver su rivalidad, desunión y anarquía, por lo que no todas atendieron esa invitación ${ }^{32}$.

En 1811 se firmó el acta de la confederación de las provincias Unidas de la Nueva Granada que en su artículo 78 estableció que formaban parte de esta todas las que al tiempo de la Revolución del 20 de julio de 1810 fueron consideradas como tales y aquellas que posteriormente se le unieran. Esta acta es importante porque señaló el reparto de competencias entre los dos niveles. Con ello se pretendió poner fin a las disputas, llamando a la unificación ante el enemigo común que era la reconquista. A las provincias se les dotó de capacidad para darse su gobierno, siempre que fuese popular, representativo y análogo al general de la Unión, entre otros poderes, cedian a la Unión; las funciones de defensa común y la imposición de tributos para la guerra, las relaciones internacionales, los correos y las monedas.

Cundinamarca inicialmente eligió la forma de monarquía constitucional, pero un año más tarde se proclamó como república, dado el nuevo escenario politico de España respecto al apresamiento del Rey. Posteriormente vinieron las

31 Jacobo Pérez Escobar, Derecho constitucional colombiano, Ediciones libreria El profesional, Bogotá, 1991, p. 87.

32 Pombo y Guerra citado por Francisco De Paula Pérez, Derecho constitucional colombiano, sexta edición, Pontificia Universidad Javeriana, Bogotá, 1992, p. 11. 
La idea de federalismo en las constituciones de Argentina y Colombia durante la ...

constituciones de 1815 de Mariquita, Antioquia, Cundinamarca y Neiva. Según De Paula Pérez ${ }^{33}$, "Todas ellas reflejan el ambiente social y se destacan por el amplio radio fijado a los derechos individuales; por el espiritu republicano sobre responsabilidad, limitación e independencia de los poderes públicos; por el anhelo de cerrar todo camino al despotismo y de condenar todo abuso de autoridad y toda mezcla o confusión en el ejercicio de esta, lo que invariablemente califican de tiránico y de contrario al espíritu de las normas fundamentales”.

El período comprendido entre 1810 y 1816 se conoce con el nombre de "Patria Boba" haciendo alusión al enfrentamiento entre federalistas y centralistas. En ese sentido, es difícil generalizar y caracterizar la nueva organización estatal. En muy poco tiempo se dieron muchas manifestaciones de organización sin que pueda definírseles de forma univoca, solo puede hablarse de una mixturas de modelos fuertemente influenciados por el norteamericano y el francés napoleónico. Se necesitaba un gobierno que cohesionara y pudiera apaciguar el recelo entre las soberanias que emanaban de cada una de las provincias. Este escenario de peleas familiares hizo propicio nuevos intentos de los patriotas por la reconquista, una vez España redefinió su relación con la Francia napoleónica.

El 7 de agosto de 1819 se consolidó la independencia absoluta y total frente a España cuando Bolivar logró vencer al ejército real en la Batalla de Boyacá. En el Congreso de Angostura del mismo año, Simón Bolívar como presidente del Ejecutivo y Francisco Antonio Zea suscribieron el estatuto de la Gran Colombia que concretó el sueño del libertador Bolivar de abandonar las formas que no convenian a su pensamiento. Entre ellas, el modelo federativo, a no copiar las leyes de otros estados y a adoptar una estructura de unidad sólida para la defensa común, y de que la República de la Nueva Granada fuera un territorio más amplio congregando en una sola nación los territorios que comprendía la Capitanía General de Venezuela y el territorio del Virreinato del Nuevo Reino de Granada, gobernado bajo un modelo unitario divido en tres departamentos, Venezuela, Quito y Cundinamarca, muy al estilo francés.

Se encuentra aquí otro modelo sui generis de fusión de Estados. Solo hasta 1822 se incorporó Ecuador cuando estuvo libre de la dominación española, libertado por Bolivar en la Batalla de Pichincha. Las deudas contraídas por los conformantes se reconocieron in solidum tomando como garantía los bienes de la nueva república. La estructura conformada se concretó en la Constitución de 1821 o de Cúcuta, reproducida casi en su totalidad en la Constitución de 1830, excepto por lo que correspondió a lograr un punto intermedio entre el centralismo y la federación. Esta Carta no tuvo vigencia real pues para esa fecha ya se había disuelto la Gran Colombia ${ }^{34}$.

José María Samper ${ }^{35}$ presenta como aciertos de la nueva Carta la unidad política que prima sobre el régimen federativo y la proscripción del modelo monárquico prefiriéndose el republicano, pero critica que no fue acertado el exceso de centralismo administrativo. El problema es que la cohesión estaba dada en torno a la figura del libertador, quien representaba la unidad nacional mientras que España representaba el enemigo. Es decir que el sentimiento estaba

\footnotetext{
33 Francisco De Paula Pérez, Derecho constitucional colombiano, op. cit., p. 20.

34 Jacobo Pérez Escobar, Derecho constitucional colombiano, op. cit., p. 105.

35 Citado por Francisco De Paula Pérez, Derecho constitucional colombiano, op. cit., p. 35.
} 
direccionado hacia una única persona, rasgo común y definitivo no solo en Colombia sino en América Latina, en donde la idolatría hacia los políticos y caudillos fue y será un factor importante de unión coyuntural.

José María Rivas Groot ${ }^{36}$ apunta que el propio Francisco de Paula Santander reconoció que la organización federal no era acorde con la situación y que dadas las circunstancias, el pueblo no podía gobernarse por ese sistema sino por uno enérgico, cuyas providencias no admitieran observaciones ni contradicciones. Es curioso este pronunciamiento de Santander de quien se dice fue un convencido del modelo federal norteamericano. El modelo unitario además de estar centralizado, tenía como elementos en su contra la distancia del territorio, factor que hubiese sido importante para dar mayores facultades a los departamentos o provincias, con el propósito de gestionar asuntos propios, en caso de haberse optado por el federalismo.

Como quiera que Bolivar se ausentara reiteradamente de la capital para llevar adelante sus campañas libertadoras, Santander en su calidad de vicepresidente asumió la jefatura del gobierno, pero vinieron las disputas y enfrentamientos entre estos personajes por las diferentes medidas santandereanas. En 1825, el Congreso también aprovechó la ausencia del General para hablar de lo perverso que era el modelo unitario y debatir sobre la posibilidad de volver al federalismo, por ende se llevaron a cabo algunas reformas tendientes a robustecer la autonomía de los departamentos y las provincias en lo económico y político, mediante una Ley Orgánica.

Hacia 1828, los partidos estaban divididos y se habian reconfigurado a favor o en contra de la causa centralista. Los bolivianos (o bolivarianos) pregonaban un centralismo fuerte y una reglamentación de las libertades públicas y las garantías individuales que las limitara. En el bando opuesto estaban los antobolivianos (o antobolivarianos) que defendian una mayor autonomía seccional y la extensión del sufragio popular ${ }^{37}$. Desde 1828 hasta 1830 Bolivar se proclamó dictador al emitir un decreto orgánico que sirvió de Ley fundamental durante ese período y suprimió la figura del vicepresidente. Finalmente, no se completó el sueño de Bolivar y se disolvió la Gran Colombia.

En 1832 se expidió una nueva Constitución con un régimen centralista que organizó el Estado de la Nueva Granada. Cada provincia estuvo a cargo de un gobernador dependiente del poder central y agente suyo, con un amplio grado de autonomía administrativa que fue otorgado a las provincias. En 1843 se organizó la república de la Nueva Granada con una Constitución conservadora que redujo sustancialmente la autonomía de las provincias para reforzar el poder central. Los constituyentes entendieron la autonomía como una debilidad para el ejecutivo, incluso esa Constitución fue tildada de monárquica.

En 1853 se inició la etapa federalista al establecerse en la Constitución las bases del sistema centro-federal decantado en la Constitución de $1858 \mathrm{y}$ finalizado en la Constitución 1863. En esta última se proclamó a Colombia como un Estado Federal fuerte y sólido durante un periodo de 23 años, es decir hasta la Constitución de 1886. El proceso de cambio de 1853 estuvo inspirado vigorosamente en las revoluciones europeas de 1848 de arraigo socialista, por lo

36 Ibíd.

37 Francisco De Paula Pérez, Derecho constitucional colombiano, op. cit., p 40. 
La idea de federalismo en las constituciones de Argentina y Colombia durante la ...

que se pensó en debilitar el poder central y dar nuevamente mayor poder a las divisiones territoriales. Se siguió con el modelo unitario pero con tendencia a la autonomía seccional, de ahí su nombre de Estado centro federal.

La Constitución dotó a las provincias de poder constitucional para su organización y se dejó al gobierno central el orden en general, la organización y administración de la hacienda, el comercio exterior, la legislación civil y penal, la demarcación del territorio, las relaciones exteriores, la declaración de guerra y la reforma a la Constitución Nacional. Igualmente, se abolió la esclavitud. Según José de la Vega ${ }^{38}$, ninguna Constitución hispanoamericana, excepto aquellas federales como la Argentina, habian llegado a tal grado de autonomía en sus provincias.

En este caso eran las provincias quienes cedian sus atribuciones al gobierno nacional. En 1855 fue necesaria la incorporación del Estado de Panamá que necesitaba atención especial por ser un territorio estratégico desde el punto político y comercial y frente al cual Estados Unidos estaba muy interesado en instalarlo como un protectorado a fin de construir el canal interoceánico. Algunos estados establecieron constituciones conservadores con fuertes tendencias limitadoras de derechos, otras en cambio resultaron ser garantistas de los derechos y libertades; por ejemplo la constitución de Vélez estableció el sufragio femenino, que en la práctica fue inoperante.

Después de la expedición de la Constitución de 1853 se desató una guerra intestina entre liberales y conservadores quienes luchaban por permanecer en el poder. Para poner fin, se estableció la Constitución de 1858, que también fue llamada de la Confederación Granadina. Esta adoptó el sistema federal en su totalidad, bajo el nombre de confederación, haciendo el respectivo reparto de competencias entre la Nación y los Estados de Antioquia, Bolivar, Boyacá, Cauca, Cundinamarca, Magdalena, Panamá y Santander que se confederaron a perpetuidad. En esta se establecieron prohibiciones a los estados tales como enajenar territorios a las potencias extranjeras, celebrar tratados directamente con ellos, permitir la esclavitud, intervenir en asuntos religiosos, impedir el comercio o porte de armas, imponer contribuciones sobre el comercio externo, $\mathrm{y}$ decretar deberes a las corporaciones o funcionarios públicos nacionales.

Lo paradójico de esta situación era que la Constitución se dio estando el Partido Conservador en el poder, lo cual representaba un acto de abnegación para poder apaciguar la guerra en la que estaba sumida la Nación. No obstante, en el año de 1859 el Congreso introdujo una serie de reformas a la Carta que para algunos estados significó el desconocimiento del pacto federal y los llevó a su separación. Este fue el caso de Cauca, que bajo gobierno del General Tomás Cipriano de Mosquera, declaró la guerra a la federación la cual estaba en cabeza de Mariano Ospina Rodríguez. Su campaña independentista abarcó otros estados como Bolivar y Santander.

En esta guerra salió victorioso el general Tomás Cipriano de Mosquera al vencer las fuerzas nacionales. Él se autoproclamó presidente provisorio de los Estados Unidos de la Nueva Granada y dictó una serie de medidas que incluían la creación del estado del Tolima, la expulsión de los jesuitas, la extinción de bienes de las comunidades religiosas y la desamortización de bienes de manos

38 Citado por Francisco De Paula Pérez, Derecho constitucional colombiano, op. cit., p. 78. 
muertas, entre otras. En señal de respeto al orden constitucional en 1861 se estableció en Bogotá un pacto o liga de los Estados, suscrito por plenipotenciarios, excepto Antioquia y Panamá.

En 1863 se expidió la Constitución Nacional de Ríonegro, abiertamente federal, en la que se establecieron los derechos y deberes de los estados, se proscribió la pena de muerte y se declaró que las comunidades religiosas eran incapaces de adquirir bienes raíces. Esto significó una guerra abierta entre la religión y el Estado. El exceso de libertades impuesto por el nuevo régimen llevó a inseguridad y caos. Los delincuentes recibían bajas penas y la guerra volvió a aparecer como una constante. En 1886 los conservadores asumieron el poder e implantaron un régimen centralista que duró más de cien años.

\section{CONCLUSIONES}

A pesar de las diferencias geográficas y culturales, la historia argentina y colombiana en el periodo de 1810 a 1853 tiene muchos puntos de encuentro. El modelo federativo aparece como una realidad y necesidad predominante para conservar la identidad y el poder local en torno a asuntos muy puntuales de las provincias y territorios predefinidos desde la colonia. Pero no fue una fórmula mágica, ni pacífica, ni tranquilizante para todos los sectores puesto que hubo otros que defendieron el modelo unitario como un arma poderosa de control sobre la totalidad del estado desde las capitales, en este caso: Santa Fe de Bogotá y Buenos Aires. La disputa llevó entonces a la configuración de partidos políticos en pro de cada causa. En Colombia a ese periodo inicial de inestabilidad se le denominó "Patria Boba", nombre que también podía encajar en la historia argentina.

Teniendo en cuenta que Estados Unidos había diseñado el modelo y lo había ensayado de una manera que pudiera pensarse que era exitosa, los federalistas quisieron imitarlo añadiendo elementos propios de la realidad local. No obstante, al no existir la claridad conceptual el modelo fue confundido con el confederativo, en el cual las provincias o estados miembros conservan su fisionomía estatal independiente con derecho a la disidencia o separación porque solo están cohesionados por asuntos estratégicos, muy diferente a lo que tendría que ocurrir en un régimen federal.

Pero más allá de la diferenciación conceptual, Argentina y Colombia debieron aprender más de la historia americana para no repetir sus propios errores. Estados Unidos tuvo un proceso diferente producto de su propia realidad en el que supieron cohesionarse para derrocar el enemigo común y supieron trabajar de forma mancomunada. Nuestros países no lo pudieron hacer y desaprovecharon oportunidades únicas de avanzar políticamente y marcar hitos históricos.

Para ambos países los años 1810 y 1853 son momentos cumbres de la historia. El primero es el año del inicio del proceso de separación de España común para ambos. 1853 es para la Argentina el inicio de una de una de las historias constitucionales más estables bajo el modelo federativo que aún subiste con algunas reformas. Para Colombia fue el inicio del periodo federativo, que infortunadamente muere 33 años más tarde en 1886. Digo que es infortunado, porque después vendrian cien años de un sistema unitario que lo único que creó 
La idea de federalismo en las constituciones de Argentina y Colombia durante la ...

fue la concentración del poder en Bogotá y el atraso de los demás territorios, lo cual no ha podido superarse plenamente. Esperemos que algún día el modelo sui generis con tendencia a la regionalización creado por la Carta del 1991 dé sus frutos.

\section{BIBLIOGRAFÍA}

Abelardo Levaggi, Confederación y federación en la génesis del estado argentino, Universidad de Buenos Aires , Buenos Aires, 2007.

Abelardo Levaggi, Constitucionalismo argentino 1810-1850, Revista Electrónica Iushistoria, $\mathrm{N}^{\circ} 2$, Buenos Aires, Universidad del Salvador, Octubre 2005.

Disponible en

http://static.scribd.com/docs/d9wd8aaxxzohf.swf?INITIAL_VIEW=width [Consultado: 2 de diciembre de 2013].

Alberto Ricardo Dalla Via, Manual de derecho constitucional, segunda edición, Abelardo Perrot, Buenos Aires, 2011.

Alfredo Gargaro, Orígenes del federalismo argentino. Tomado de http://www.fundacioncultural.org/revista/nota1_33.html [Consultado: 20 de noviembre de 2013].

Arturo Enrique Sampay, Las constituciones de la Argentina 18101972,Eudeba, Buenos Aires, 1974.

Celso Ramón Lorenzo, Manual de historia constitucional argentina, Editorial Juris, Buenos Aires, 2000.

Francisco De Paula Pérez, Derecho constitucional colombiano, sexta edición, Pontificia Universidad Javeriana, Bogotá, 1992.

Georges Burdeau, Derecho Constitucional e Instituciones Políticas, traducción de la $18^{\mathrm{a}}$ ed. francesa realizada por Ramón Falcón Tello, Editora Nacional Cultura y Sociedad Torregalindo, Madrid, 1981.

Germán Bidart Campos, Historia Política y Constitucional Argentina, Tomo I, Ediar, Buenos Aires, 1976.

Hernán Alejandro Olano García, Constitucionalismo Histórico, Ediciones Librería El Profesional, Bogotá, 2002.

Horacio Rosatti, Tratado de derecho constitucional, Tomo II, Rubinzal Culzoni Editores, Buenos Aires, 2010.

Jacobo Pérez Escobar, Derecho constitucional colombiano, Ediciones librería El profesional, Bogotá, 1991.

José Carlos Chiaramonte, "El federalismo argentino en la primera mitad del siglo XIX" en Marcelo Carmagnani (coord.). Federalismos latinoamericanos: México/Brasil/Argentina, Fondo de Cultura económica, México, 1993.

Juan Carlos Gioja, Constitución de la Nación Argentina, Corte Suprema de Justicia de la Nación / Biblioteca del Congreso de la Nación / Biblioteca Nacional, Buenos Aires, 2010. 
Raúl Gustavo Ferreyra, "1852: Sobre las bases de Juan Bautista Alberdi y la constitución federal en el tiempo", Revista Contextos 3, Defensoría del Pueblo de la Ciudad Autónoma de Buenos Aires, Buenos Aires, 2012.

Enviado el (Submission date): 21/01/2015

Aceptado el (Acceptance date): 17/04/2015 